\title{
Changes in Sitting Time and Sitting Fragmentation after a Workplace Sedentary Behaviour Intervention
}

\author{
Jasmin Hutchinson ${ }^{1, *(\mathbb{D})}$, Samuel Headley ${ }^{1}$, Tracey Matthews ${ }^{2}$, Greg Spicer ${ }^{1}$, \\ Kristen Dempsey ${ }^{3}$, Sarah Wooley ${ }^{1}$ and Xanne Janssen ${ }^{4}$ \\ 1 Department of Exercise Science and Sport Studies, Springfield College, 263 Alden Street, Springfield, \\ MA 01109, USA; sheadley@springfieldcollege.edu (S.H.); gspicer@springfieldcollege.edu (G.S.); \\ swooley@springfieldcollege.edu (S.W.) \\ 2 School of Health, Physical Education and Recreation, Springfield College, 263 Alden Street, Springfield, \\ MA 01109, USA; tmatthews@springfieldcollege.edu \\ 3 Cardiac Rehab/Non-Invasive Cardiology, Newton-Wellesley Hospital, 2014 Washington Street, Newton, \\ MA 02462, USA; dempseykristen1214@gmail.com \\ 4 School of Psychological Science and Health, University of Strathclyde, 16 Richmond Street, \\ Glasgow G1 1XQ, UK; xanne.janssen@strath.ac.uk \\ * Correspondence: jhutchinson@springfieldcollege.edu; Tel.: +1-413-748-3601
}

Received: 4 May 2018; Accepted: 30 May 2018; Published: 1 June 2018

\begin{abstract}
Prolonged sedentary behaviour (SB) has shown to be detrimental to health. Nevertheless, population levels of SB are high and interventions to decrease SB are needed. This study aimed to explore the effect of a personalized intervention aimed at reducing SB and increasing breaks in SB among college employees. A pre-experimental study design was used. Participants $(n=36)$ were recruited at a college in Massachusetts, USA. SB was measured over 7 consecutive days using an activPAL3 accelerometer. Following baseline measures, all participants received a personalized SB consultation which focused on limiting bouts of SB >30 min, participants also received weekly follow-up e-mails. Post-intervention measures were taken after 16 weeks. Primary outcome variables were sedentary minutes / day and SB bouts $>30 \mathrm{~min}$. Differences between baseline and follow-up were analyzed using paired t-tests. The intervention did not change daily sedentary time $(-0.48 \% ; p>0.05)$. The number of sedentary bouts $>30$ min decreased significantly by 0.52 bouts $/$ day $(p=0.010)$. In this study, a personalized SB intervention was successful in reducing number of bouts $>30 \mathrm{~min}$ of SB. However, daily sedentary time did not reduce significantly. These results indicate that personalized, consultation-based interventions may be effective if focused on a specific component of SB.
\end{abstract}

Keywords: sitting time; occupational; sedentary fragmentation; objective measurement

\section{Introduction}

Sedentary behavior (SB), defined as "any waking behavior characterized by an energy expenditure $\leq 1.5$ metabolic equivalents (METS) while in a sitting or reclining posture" [1] is an important risk factor for poor health. Recent systematic reviews have linked high levels of SB to many negative health outcomes such as cardiovascular disease, type 2 diabetes, certain cancers, and all-cause mortality, independent of physical activity [2-6]. Nevertheless, sedentary behaviour is on the rise, particularly in developed countries. Adults in the United States [7], Norway [8] and Sweden [9] spend approximately two thirds of the waking day sedentary. Causes of SB in both developed and developing countries include reduced frequency of physical activity, increased sedentary leisure pursuits at home and increased amounts of seated technical work or desk-based office work [10]. Data from a range of industrialised countries indicate that increased sedentariness at work is an international 
phenomenon [11]. For example, Australian office workers reportedly spend $82 \%$ of their working day seated [12]. The workplace has been recognized as an important setting for the implementation of strategies to promote physical activity and reduce SB [13]. The workplace also presents opportunities to promote active commuting, and to build upon the rapidly growing practice of mobile health (or mHealth) to harness the potential of technology to help improve the health and wellbeing of all individuals [14]. Workplace SB interventions can be an effective way to reduce sedentary time and increase breaks in sedentary behaviour [15]. Most of these interventions have targeted the environment, for example implementing sit-stand desks or active workstations [16,17], and while these interventions can be effective, the question is whether these interventions are affordable and feasible to implement on a larger scale. A more affordable strategy, which is able to reach many people at once, is the use of digital applications to prompt employees to stand up at regular intervals [18]. However these interventions often lack an informative component, thereby failing to increase participant's knowledge as to why they should be reducing SB. There is also a need to assess longer-term effects of such interventions. Another cost-effective workplace intervention recommended by the World Health Organization is behavioural counseling [19].

Previous research in physical activity has shown that including concepts such as personalized goal-setting and information prompts are important concepts to implement in behaviour change interventions [20]. In addition, individualized consultation approaches have shown to be an effective way to target these concepts and result in successful behaviour change in physical activity and dietary studies $[20,21]$. However, relatively few studies have implemented a personalized consultation based upon current patterns of behaviour. An exception is a small pilot study by Fitzsimons et al. in which community dwelling older adults (mean age $=68 \pm 6$ years) received a personalized SB consultation incorporating feedback from an activPAL activity monitor. Objectively measured daily time spent sitting/lying was reduced by $2.2 \%$ or $25 \mathrm{~min}$ per $24 \mathrm{~h}$ over 2 weeks. The intervention also significantly increased total time spent stepping by $13 \mathrm{~min} /$ day [22]. To the best of our knowledge, no study has taken a personalized approach to SB behavioural counseling in the workplace. Therefore, this study aimed to explore the feasibility and effectiveness of an individually tailored behavioural consultation aimed at reducing SB and increasing breaks in sedentary time in college workers.

\section{Materials and Methods}

\subsection{Study Design}

This study aimed to test the feasibility and pilot the effectiveness of a personalized, consultation based SB intervention in the workplace. The study was conducted as a pre-experimental (one group pretest-posttest) study design. Participants were enrolled in the study between September-December 2016 and follow-up data were collected in February-May 2017. The study was reviewed and approved by the Institutional Review Board of the College and data were only collected on individuals who gave their informed consent to participate.

\subsection{Participants}

Thirty-six participants $(7$ men, 29 women; mean age, $51.1 \pm 11.1$ years; mean BMI, $29.2 \pm 7.6 \mathrm{~kg} / \mathrm{m}^{2}$ ) were recruited from Springfield College (Springfield, MA, USA). All College employees received a recruitment email about the study at the beginning of the fall semester (i.e., September 2016). To be eligible to participate, participants had to be at least 18 years old and classified as full-time employees at the institution. Figure 1 shows the number of participants who were screened for eligibility, received the intervention, attended follow-up testing, and were included in the final analysis. 


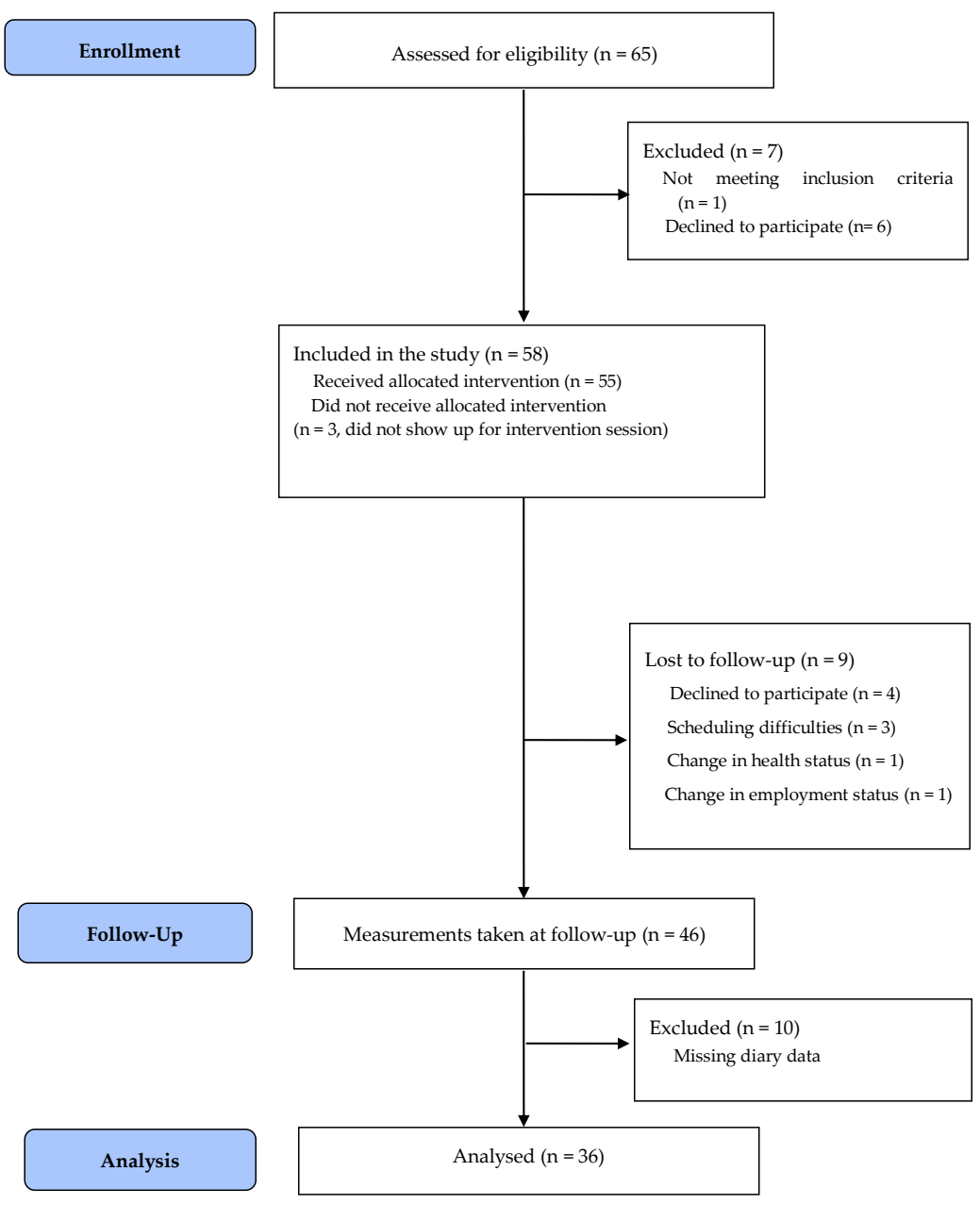

Figure 1. CONSORT flow diagram showing the flow of participants through each stage of the study.

\subsection{Procedures}

During the first visit, participants provided informed consent and completed a brief demographic questionnaire. Height and weight were taken following standardized methods and participants were fitted with an activPAL3 monitor [23]. The monitor was attached directly to the midline anterior aspect of the participants' right thigh, mid-way between the hip and the knee in the correct orientation as outlined by the manufacturer's instructions. A nitral sleeve was used for waterproofing, and the monitor was secured to the thigh using Tegaderm dressing. Participants wore the activPal 3 monitor continuously 24-h per day for seven consecutive days, after which the device was returned to the laboratory. During the 7-day wear period, participants were asked to record in a diary their bed (i.e., "lights out") and wake times as well as the times they were at work each day.

A second visit was scheduled for one week after the activPAL3 monitor was returned, this was done in order to allow time for data processing. During this visit, participants met in small groups of 2-5 to participate in a personalized SB consultation, as outlined below. A third and final visit was scheduled 16-weeks following the behavioural intervention, at which time participants were asked to wear the activPAL3 for another seven consecutive days.

\subsection{Intervention}

Phase One: The behaviour change intervention consisted of one 45-min face-to-face consultation session conducted by a member of the research team, and a series of weekly follow-up emails delivered over the ensuing 16 weeks. The theoretical underpinning of the intervention was Lewin's force field 
theory. Lewin (1947) put forward the idea, that behavioural status quo represents an equilibrium between forces favoring change (i.e., driving forces) and barriers to change (i.e., restraining forces) [24]. For a goal-directed activity to be successfully implemented, the magnitude of the driving force needs to match the magnitude of the restraining force [25].

The behavioural intervention sought to increase driving forces for change and reduce restraining forces. The behavioural intervention was delivered in five stages. The first stage focused on increasing participant's knowledge of SB and the health effects of SB. During the second stage participants identified specific driving forces toward decreasing SB (the "why" of behaviour change). Participants also reviewed and reflected upon their current SB patterns based on their personal activPAL data. Using a printout of the 7-day report participants were able to identify the most sedentary periods of their work day and map these time periods to specific work tasks and behaviours. Stage 3 focused on finding feasible ways to reduce SB throughout the working day; this was achieved through brainstorming and facilitated group discussion. In the fourth stage potential barriers to change (i.e., restraining factors) were identified and solutions were sought, again through a process of self-reflection and group discussion. In the final stage additional behavioural strategies were offered (if not self-identified by the group) and participants created feasible goals to reduce their SB at work, specifically to break up bouts of SB greater than $30 \mathrm{~min}$. Table 1 details the intervention in terms of specific behaviour change techniques, to allow for coding using the Behaviour Change Technique Taxonomy [26].

Table 1. Behavioural Intervention.

\begin{tabular}{|c|c|c|c|}
\hline Intervention Stage & Objectives & Behaviour Change Techniques & Example \\
\hline Stage 1 & $\begin{array}{l}\text { Increase knowledge or understanding } \\
\text { of sedentary behaviour (SB) health risks }\end{array}$ & $\begin{array}{l}\text { Information about health consequences } \\
\text { and the salience of such consequences } \\
\text { from credible sources }\end{array}$ & $\begin{array}{l}\text { Share information on health risks and } \\
\text { consequences associated with SB using } \\
\text { handout from the American College of } \\
\text { Sports Medicine. }\end{array}$ \\
\hline Stage 2 & $\begin{array}{l}\text { Review and reflect upon own SB } \\
\text { patterns using activPal output }\end{array}$ & $\begin{array}{l}\text { Develop discrepancy between current } \\
\text { behaviour and goal. } \\
\text { Consider pros and cons of } \\
\text { decreasing SB. }\end{array}$ & $\begin{array}{l}\text { Review current patterns of SB relative } \\
\text { to desired SB. } \\
\text { List and compare the advantages and } \\
\text { disadvantages of sitting less at work. }\end{array}$ \\
\hline \multirow{4}{*}{ Stage 3} & $\begin{array}{l}\text { Develop strategies to decrease SB in } \\
\text { the workplace }\end{array}$ & Action planning & $\begin{array}{l}\text { Plan times for standing breaks during } \\
\text { the workday. }\end{array}$ \\
\hline & & Prompts/cues & $\begin{array}{l}\text { Keep a set of sneakers or comfortable } \\
\text { shoes in the office. }\end{array}$ \\
\hline & & Habit formation & Stand up every time the phone rings. \\
\hline & & $\begin{array}{l}\text { Restructuring the physical and } \\
\text { social environment }\end{array}$ & $\begin{array}{l}\text { Purchase or build a sit-stand desk. } \\
\text { Promote standing/walking meetings. }\end{array}$ \\
\hline \multirow{3}{*}{ Stage 4} & $\begin{array}{l}\text { Identify barriers to decreasing SB in the } \\
\text { workplace and provide solutions }\end{array}$ & Problem solving & $\begin{array}{l}\text { Brainstorm ways to combine work with } \\
\text { movement (e.g., walking office hours). }\end{array}$ \\
\hline & & Prompts/cues & $\begin{array}{l}\text { Set electronic reminders to take } \\
\text { standing breaks. }\end{array}$ \\
\hline & & Behaviour substitution & $\begin{array}{l}\text { Use a bathroom on a different floor of } \\
\text { the building. }\end{array}$ \\
\hline Stage 5 & Set goal to break up SB bouts $>30 \mathrm{~min}$ & Goal setting & $\begin{array}{l}\text { Make a behavioural resolution relative } \\
\text { to target behaviour on reducing SB } \\
\text { bouts }>30 \mathrm{~min}\end{array}$ \\
\hline
\end{tabular}

Phase 2: Following the behavioural consultation the intervention group received weekly e-mail prompts/reminders to break up prolonged bouts of sitting at work. Emails were sent every Monday morning during work hours. Content of the emails varied between short simple messages, graphical illustrations, information sharing (e.g., links to relevant content, or "did you know ... ?" statements) and specific tips on how to reduce or interrupt workplace sitting. Emails were designed to target both affective and cognitive attitudes [27] toward SB and included a combination of both gain-framed and loss-framed message content [28]. Full content of the weekly emails can be requested from the first author. 


\subsection{Outcome Measures and Statistical Analysis}

Sedentary behaviour was measured using an activPAL3 accelerometer. The activPAL3 classifies a person's behaviour into sitting/lying, standing and stepping and has been shown to be a valid and reliable measure of SB in adults [29]. Data were analysed using the event files from the activPAL3 and a personalized macro (available upon request from Xanne Janssen). Primary outcome measures were the average percentage of time spent sitting or lying per day/working day and the average number of bouts per day/working day lasting more than $30 \mathrm{~min}$. Secondary outcomes were the average percentage of time spent standing and stepping per day/working day, sitting to upright transitions (lasting more than $1 \mathrm{~min}$ ) and the average number of SB bouts lasting 10-19.99 $\mathrm{min}, 20-29.99 \mathrm{~min}$ and $>30 \mathrm{~min}$ per day/working day.

Paired $t$-tests were used to compare time spent sitting/lying, standing and stepping, number of sitting to upright transitions and number of bouts lasting 10-10.99 $\mathrm{min}, 20-29.99 \mathrm{~min}$ and $>30 \mathrm{~min}$ between baseline and follow-up. A covariate model was considered, with BMI as a covariate, but non-significant correlations indicated that the basic assumption that the covariate is related to the dependent variables [30] was not met. Sedentary, standing and stepping time was expressed in percentages in the analysis to control for differences in waking time. A $p$-value of $<0.05$ was considered statistically significant. All statistical analyses were conducted in SPSS version 25 (SPSS, Inc., Chicago, IL, USA).

\section{Results}

Thirty-six participants provided informed consent and took part in the intervention. All participants provided at least 5 days of valid activPAL data for both baseline and follow-up measures. At baseline, participants spent an average of $9.4 \mathrm{~h}$ per day sedentary with no significant difference between females and males during the waking day $(p=0.563)$. See Table 2 .

Table 2. Participant baseline data.

\begin{tabular}{cc}
\hline Variable & Mean (SD) \\
\hline Sedentary time (h/day) & $9.4(1.5)$ \\
Standing time (h/day) & $4.5(1.3)$ \\
Stepping time (h/day) & $1.9(0.5)$ \\
Sedentary time (h/working day) & $4.5(1.5)$ \\
Standing time (h/working day) & $2.5(1.1)$ \\
Stepping time (h/day) & $1.0(0.5)$ \\
\hline
\end{tabular}

\subsection{Whole Day Sedentary Behaviour}

Intervention results are displayed in Table 3. Briefly, participants spent an average of $59.1 \%$ (SD 8.3) of their waking day sedentary at baseline $(9.4 \pm 1.5 \mathrm{~h} /$ day) and this decreased to $58.6 \%$ (SD 11.2$)$ at follow up $(9.1 \pm 2.1 \mathrm{~h} /$ day; $p=0.611)$. At baseline participants accumulated 4.8 bouts of SB greater than 30 min per day (SD 1.3), this decreased significantly to 4.3 bouts per day (SD 1.6) at follow-up $(p=0.010)$.

Table 3. Intervention outcomes whole day.

\begin{tabular}{cccc}
\hline Variable & Baseline & Follow-Up & $p$-Value \\
\hline Sedentary time (\%) & $59.1(8.3)$ & $58.6(11.2)$ & 0.611 \\
Standing time (\%) & $28.5(7.4)$ & $29.0(9.8)$ & 0.649 \\
Stepping time (\%) & $12.3(3.5)$ & $12.5(4.3)$ & 0.765 \\
Bouts 10-19.99 min & $6.8(2.2)$ & $6.8(2.2)$ & 0.982 \\
Bouts 20-20.99 min & $3.1(0.9)$ & $3.0(1.0)$ & 0.917 \\
Bouts > 30 min & $4.8(1.3)$ & $4.3(1.6)$ & 0.010 \\
Sitting to upright transitions & $39.3(7.8)$ & $37.6(7.8)$ & 0.175 \\
\hline
\end{tabular}




\subsection{Working Day Sedentary Behaviour}

Intervention results during the working day are displayed in Table 4 . No significant changes between baseline and follow-up were found in any of the outcomes. Participants spent an average of $56.0 \%$ (SD 15.2) of their working day sedentary at baseline (4.5 $\pm 1.5 \mathrm{~h} /$ day) and $54.8 \%$ (SD 17.4 ) at follow up ( $4.4 \pm 1.8 \mathrm{~h} /$ day; $p=0.575)$. At baseline participants accumulated $2.0 \mathrm{SB}$ bouts greater than 30 min per working day (SD 1.3), and at follow-up this was 1.9 bouts per working day (SD 1.4) at follow-up $(p=0.663)$.

Table 4. Intervention outcomes working day.

\begin{tabular}{cccc}
\hline Variable & Baseline & Follow-Up & $p$-Value \\
\hline Sedentary time (\%) & $56.0(15.2)$ & $54.8(17.4)$ & 0.575 \\
Standing time (\%) & $30.9(13.3)$ & $32.4(16.8)$ & 0.428 \\
Stepping time (\%) & $13.1(7.1)$ & $12.8(8.8)$ & 0.748 \\
Bouts 10-19.99 min & $3.9(1.9)$ & $4.0(2.0)$ & 0.886 \\
Bouts 20-20.99 min & $1.6(0.9)$ & $1.7(0.9)$ & 0.575 \\
Bouts > 30 min & $2.0(1.3)$ & $1.9(1.4)$ & 0.663 \\
Sitting to upright transitions & $22.3(8.2)$ & $21.3(7.7)$ & 0.415 \\
\hline
\end{tabular}

\section{Discussion}

A personalized behavioural intervention aimed at reducing SB and increasing breaks in SB among college employees resulted in a significant decrease in bouts of SB greater than 30 min during the whole day, but not specifically the workday. This is an important finding given the fact that engaging in prolonged periods of unbroken SB is associated with poor health outcomes [31]. The fact that SB bouts were reduced across the whole day, but not specifically the workday is somewhat surprising given that the behavioural intervention was targeted specifically toward SB at work. One possible explanation for this is that participants had more control over their environment and activities outside of work. Therefore, it is possible that the message of the intervention was received, but was harder to put into place within the confines of the working environment. A multi-level intervention, to include environmental restructuring, policy change, and addressing social norms (e.g., walking/standing meetings) may be required to impact on employees' workplace behaviour. Intervening simultaneously at multiple levels within and across levels and settings is thought to result in greater and longer-lasting behaviour change [32]. For example, a short-term (4-week) multilevel intervention comprising organizational, environmental, and individual change elements to reduce workplace sitting achieved sizeable ( $>2$-h per 8 -h workday; $-26.5 \%$ of workplace time) reductions in workplace sitting [15]. Relatively little is known as to how health promotion programs targeted at the individual behaviour in the worksite might influence workplace norms, the social environment of the workplace and/or workplace policies [33]. However, from an ecological perspective [34] it seems reasonable to assume that a reciprocal relationship might exist. Thus, there is a need for future SB interventions to evaluate program effects at multiple levels.

In the present study, an individually-tailored behavioural intervention did not impact daily sedentary time. This is not entirely unexpected, as the focus of the intervention was breaking up prolonged ( $>30-\mathrm{min}$ ) bouts of SB. Evans et al. reported similar results, with no significant decrease in overall SB but a significant reduction of SB $>30 \mathrm{~min}$ (1.1 bout/day) in participants who received an educational and email prompts intervention compared to those who only received the educational content [35]. Extending the consultation time, or providing a second consultation, may have allowed for time to focus on decreasing total $\mathrm{SB}$, however we did not want to place a greater burden on participants' time. The study was also designed to focus on a single behaviour, as participants can feel overwhelmed when asked to change multiple behaviours simultaneously [36].

Previous studies focusing on reducing SB in the workplace have shown conflicting results. A recent systematic review highlighted that studies which implemented environmental changes 
(e.g., sit-stand desks) noted significant reductions in SB during the working day [37]. However, as mentioned previously, the adoption of these interventions in real life is questionable due to high cost and resources required. When focusing on interventions similar to the present study, which only included educational/behavioural components (e.g., provide information on consequences of behaviour to the individual; goal setting; use prompts/cues), results were inconclusive. However, all interventions showed a reduction in sitting time (pooled reduction of $-15.5 \mathrm{~min} / 8$-h workday (95\% CI: $-22.9,-8.2))$ which is slightly higher than the mean reduction in the current study which was only about $6 \mathrm{~min}$ during the working day. One reason for this could be the relatively low level of SB participants in the current study exhibited. For example, Evans et al. (2012) reported their participants spent $78 \%$ of their working day seated compared to $56 \%$ in the current sample [35].

Important strengths of this study include the within subject design and the length of time (16 weeks) between the face-to-face intervention and follow-up testing. Also, the detailed objective measurement of multiple features of SB with a validated device designed to differentiate sitting and standing behaviours. The major limitations of this study are the lack of a control group, and a small $(n=36)$ and relatively homogeneous sample. The lack of a suitable control intervention means that our pre-experimental study sheds no light on whether other interventions would result in similar changes. Future controlled trials are warranted which also seek to confirm the current results in larger, more diverse groups. A larger sample size would also present the opportunity to determine whether the observed effects might be moderated by participant characteristics (e.g., age, BMI, occupational role). Finally, it is worth considering that the use of the activPAL device may have resulted in some reactivity (i.e., change in behaviour) of participants due to awareness of being monitored. However, several studies have shown no evidence of reactivity to wearable technology such as accelerometers and pedometers [38,39].

\section{Conclusions}

In this feasibility and pilot study, a personalized SB intervention was successful in reducing number of SB bouts greater than 30 min during the whole day but not the working day. Overall daily sedentary time, number of sitting to upright transitions and number of sedentary bouts less than $30 \mathrm{~min}$ were not significantly reduced. These results indicate that consultation based interventions may be effective if goal setting is focused on a specific component of SB (e.g., reducing 30-min bouts, including 10-min active breaks every hour). This study did not include a control group and the results of the study should be confirmed by more structured randomized controlled trials.

Author Contributions: J.H., S.H. and T.M. conceived and designed the experiments; J.H. developed and implemented the behavioural intervention, G.S., K.D. and S.W. were responsible for data collection and the organization of the study; X.J. and T.M. analyzed the data; X.J. created the analysis macro; J.H. and X.J. wrote the paper, all authors provided feedback on the draft manuscript and approved the final version.

Acknowledgments: The authors would like to acknowledge the wonderful assistance that we received from the administrators, faculty, and staff at the College for participating in this study. We would also like to thank Brendan O'Neil, Anna Platz, Patricia Rousseau and Bassey Apkan for their assistance with the intervention. This study was supported by funds from the Academic Affairs Division of Springfield College and from the School of Health, Physical Education, and Recreation at Springfield College.

Conflicts of Interest: The authors declare no conflict of interest. The founding sponsors had no role in the design of the study; in the collection, analyses, or interpretation of data; in the writing of the manuscript, and in the decision to publish the results.

\section{References}

1. Sedentary Behaviour Research Network. Letter to the editor: Standardized use of the terms "sedentary" and "sedentary behaviours". Appl. Physiol. Nutr. Metab. 2012, 37, 540-542.

2. Benatti, F.B.; Larsen, S.A.; Kofoed, K.; Nielsen, S.T.; Harder-Lauridsen, N.M.; Lyngbaek, M.P.; Eriksen, D.; Karstoft, K.; Krogh-Madsen, R.; Pedersen, B.K.; et al. Intermittent Standing but not a moderate exercise bout reduces postprandial glycemia. Med. Sci. Sports Exerc. 2017, 49, 2305-2314. [CrossRef] [PubMed] 
3. Chastin, S.F.; Palarea-Albaladejo, J.; Dontje, M.L.; Skelton, D.A. Combined effects of time spent in physical activity, sedentary behaviors and sleep on obesity and cardio-metabolic health markers: A novel compositional data analysis approach. PLoS ONE 2015, 10, e0139984. [CrossRef] [PubMed]

4. Katzmarzyk, P.T.; Church, T.S.; Craig, C.L.; Bouchard, C. Sitting time and mortality from all causes, cardiovascular disease, and cancer. Med. Sci. Sports Exerc. 2009, 41, 998-1005. [CrossRef] [PubMed]

5. Lyden, K.; Keadle, S.K.; Staudenmayer, J.; Braun, B.; Freedson, P.S. Discrete features of sedentary behavior impact cardiometabolic risk factors. Med. Sci. Sport Exerc. 2015, 47, 1079-1086. [CrossRef] [PubMed]

6. Wennberg, P.; Boraxbekk, C.-J.; Wheeler, M.; Howard, B.; Dempsey, P.C.; Lambert, G.; Eikelis, N.; Larsen, R.; Sethi, P.; Occleston, J.; et al. Acute effects of breaking up prolonged sitting on fatigue and cognition: A pilot study. BMJ Open 2016, 6, e009630. [CrossRef] [PubMed]

7. Matthews, C.E.; Chen, K.Y.; Freedson, P.S.; Buchowski, M.S.; Beech, B.M.; Pate, R.R.; Troiano, R.P. Amount of time spent in sedentary behaviors in the United States, 2003-2004. Am. J. Epidemiol. 2008, 167, 875-881. [CrossRef] [PubMed]

8. Ekblom-Bak, E.; Olsson, G.; Ekblom, Ö.; Ekblom, B.; Bergström, G.; Börjesson, M. The daily movement pattern and fulfilment of physical activity recommendations in Swedish middle-aged adults: The SCAPIS pilot study. PLoS ONE 2015, 10, e0126336. [CrossRef] [PubMed]

9. Hagströmer, M.; Troiano, R.P.; Sjöström, M.; Berrigan, D. Levels and patterns of objectively assessed physical activity-A comparison between Sweden and the United States. Am. J. Epidemiol. 2010, 171, 1055-1064. [CrossRef] [PubMed]

10. Brownson, R.C.; Boehmer, T.K.; Luke, D.A. Declining rates of physical activity in the United States: What are the contributors? Ann. Rev. Public Health 2005, 26, 421-443. [CrossRef] [PubMed]

11. Straker, L.; Mathiassen, S.E. Increased physical work loads in modern work-A necessity for better health and performance? Ergonomics 2009, 52, 1215-1225. [CrossRef] [PubMed]

12. Parry, S.; Straker, L. The contribution of office work to sedentary behaviour associated risk. BMC Public Health 2013, 13, 296. [CrossRef] [PubMed]

13. Castillo-Retamal, M.; Hinckson, E.A. Measuring physical activity and sedentary behaviour at work: A review. Work 2011, 404, 345-357. [CrossRef]

14. Labrique, A.B.; Vasudevan, L.; Kochi, E.; Fabricant, R.; Mehl, G. mHealth innovations as health system strengthening tools: 12 common applications and a visual framework. Glob. Health Sci. Pract. 2013, 1, 160-171. [CrossRef] [PubMed]

15. Healy, G.N.; Eakin, E.G.; LaMontagne, A.D.; Owen, N.; Winkler, E.A.H.; Wiesner, G.; Gunning, L.; Neuhaus, M.; Lawler, S.; Fjeldsoe, B.S.; et al. Reducing sitting time in office workers: Short-term efficacy of a multicomponent intervention. Prev. Med. 2013, 57, 43-48. [CrossRef] [PubMed]

16. Alkhajah, T.A.; Reeves, M.M.; Eakin, E.G.; Winkler, E.A.; Owen, N.; Healy, G.N. Sit-stand workstations: A pilot intervention to reduce office sitting time. Am. J. Prev. Med. 2012, 43, 298-303. [CrossRef] [PubMed]

17. John, D.; Thompson, D.L.; Raynor, H.; Bielak, K.; Rider, B.; Bassett, D.R. Treadmill workstations: A worksite physical activity intervention in overweight and obese office workers. J. Phys. Act. Health 2011, 8, 1034-1043. [CrossRef] [PubMed]

18. Urda, J.L.; Lynn, J.S.; Gorman, A.; Larouere, B. Effects of a minimal workplace intervention to reduce sedentary behaviors and improve perceived wellness in middle-aged women office workers. J. Phys. Act. Health 2016, 13, 838-844. [CrossRef] [PubMed]

19. World Health Organization. Tackling NCDs: 'Best Buys' and Other Recommended Interventions for the Prevention and Control of Noncommunicable Disease; World Health Organization: Geneva, Switzerland, 2017.

20. Greaves, C.J.; Sheppard, K.E.; Abraham, C.; Hardeman, W.; Roden, M.; Evans, P.H.; Schwarz, P. Systematic review of reviews of intervention components associated with increased effectiveness in dietary and physical activity interventions. BMC Public Health 2011, 11, 119. [CrossRef] [PubMed]

21. Chau, J.Y.; van der Ploeg, H.P.; van Uffelen, J.G.; Wong, J.; Riphagen, I.; Healy, G.N.; Gilson, N.D.; Dunstan, D.W.; Bauman, A.E.; Owen, N.; et al. Are workplace interventions to reduce effective sitting? A systematic review. Prev Med. 2010, 51, 352-356. [CrossRef] [PubMed]

22. Fitzsimons, C.F.; Kirk, A.; Baker, G.; Michie, F.; Kane, C.; Mutrie, N. Using an individualised consultation and activPAL ${ }^{\mathrm{TM}}$ feedback to reduce sedentary time in older Scottish adults: Results of a feasibility and pilot study. Prev. Med. 2013, 57, 718-720. [CrossRef] [PubMed] 
23. Edwardson, C.L.; Winkler, E.A.; Bodicoat, D.H.; Yates, T.; Davies, M.J.; Dunstan, D.W.; Healy, G.N. Considerations when using the activPAL monitor in field-based research with adult populations. J. Sport Health Sci. 2017, 6, 162-178. [CrossRef]

24. Lewin, K. Frontiers in group dynamics: I. Concept, method and reality in social sciences; social equilibria and social change. Hum. Relat. 1947, 1, 5-41. [CrossRef]

25. Kruglanski, A.W.; Bélanger, J.J.; Chen, X.; Köpetz, C.; Pierro, A.; Mannetti, L. The energetics of motivated cognition: A force-field analysis. Psychol. Rev. 2012, 119, 1-20. [CrossRef] [PubMed]

26. Michie, S.; Richardson, M.; Johnston, M.; Abraham, C.; Francis, J.; Hardeman, W.; Eccles, M.P.; Cane, J.; Wood, C.E. The behavior change technique taxonomy (v1) of 93 hierarchically clustered techniques: Building an international consensus for the reporting of behavior change interventions. Ann. Behav. Med. 2013, 46, 81-95. [CrossRef] [PubMed]

27. Conner, M.; Rhodes, R.E.; Morris, B.; McEachan, R.; Lawton, R. Changing exercise through targeting affective or cognitive attitudes. Psychol. Health 2011, 26, 133-149. [CrossRef] [PubMed]

28. O'Keefe, D.J.; Jensen, J.D. The relative persuasiveness of gain-framed loss-framed messages for encouraging disease prevention behaviors: A meta-analytic review. J. Health Commun. 2007, 12, 623-644. [CrossRef] [PubMed]

29. Lyden, K.; Kozey-Keadle, S.L.; Staudenmayer, J.W.; Freedson, P.S. Validity of two wearable monitors to estimate breaks from sedentary time. Med. Sci. Sports Exerc. 2012, 44, 2243-2252. [CrossRef] [PubMed]

30. Warner, R. Applied Statistics from Bivariate through Multivariate Techniques; SAGE: Washington, DC, USA, 2013.

31. Healy, G.N.; Matthews, C.E.; Dunstan, D.W.; Winkler, E.A.; Owen, N. Sedentary time and cardio-metabolic biomarkers in US adults: NHANES 2003-06. Eur. Heart J. 2011, 32, 590-597. [CrossRef] [PubMed]

32. Manini, T.M.; Carr, L.J.; King, A.C.; Marshall, S.; Robinson, T.N.; Rejeski, W.J. Interventions to reduce sedentary behavior. Med. Sci. Sports Exerc. 2015, 47, 1306-1310. [CrossRef] [PubMed]

33. O'Donnell, M.P. (Ed.) Health Promotion in the Workplace, 3rd ed.; Cengage Learning: Boston, MA, USA, 2002.

34. Sallis, J.F.; Cervero, R.B.; Ascher, W.; Henderson, K.A.; Kraft, M.K.; Kerr, J. An ecological approach to creating active living communities. Ann. Rev. Public Health 2006, 27, 297-322. [CrossRef] [PubMed]

35. Evans, R.E.; Fawole, H.O.; Sheriff, S.A.; Dall, P.M.; Grant, P.M.; Ryan, C.G. Point-of-choice prompts to reduce sitting time at work: A randomized trial. Am. J. Prev. Med. 2012, 43, 293-297. [CrossRef] [PubMed]

36. Spring, B.; Doran, N.; Pagoto, S.; Schneider, K.; Pingitore, R.; Hedeker, D. Randomized controlled trial for behavioral smoking and weight control treatment: Effect of concurrent versus sequential intervention. J. Consult. Clin. Psychol. 2004, 72, 785-796. [CrossRef] [PubMed]

37. Chu, A.H.Y.; Ng, S.H.; Tan, C.S.; Win, A.M.; Koh, D.; Müller-Riemenschneider, F. A systematic review and meta-analysis of workplace intervention strategies to reduce sedentary time in white-collar workers. Obes. Rev. 2016, 17, 467-481. [CrossRef] [PubMed]

38. Behrens, T.K.; Dinger, M.K. Motion sensor reactivity in physically active young adults. Res. Q. Exerc. Sport 2007, 78, 1-8. [CrossRef] [PubMed]

39. Davis, R.E.; Loprinzi, P.D. Examination of accelerometer reactivity among a population sample of children, adolescents, and adults. J. Phys. Act. Health 2016, 13, 1325-1332. [CrossRef] [PubMed]

(C) 2018 by the authors. Licensee MDPI, Basel, Switzerland. This article is an open access article distributed under the terms and conditions of the Creative Commons Attribution (CC BY) license (http:// creativecommons.org/licenses/by/4.0/). 